\title{
Cardiovascular diseases and hippocampal infarcts
}

\begin{tabular}{|r|l|}
\hline Journal: & Hippocampus \\
\hline Manuscript ID: & HIPO-09-193.R1 \\
\hline Wiley - Manuscript type: & Research Article \\
\hline Keywords: & $\begin{array}{l}\text { post-mortem study, hippocampus, infarct, cardiovascular disease, } \\
\text { histology }\end{array}$ \\
\hline \multicolumn{2}{|l}{} \\
\hline
\end{tabular}

\section{今) ScholaroNE" \\ Manuscript Central}




\section{Cardiovascular diseases and}

\section{hippocampal infarcts}

Tuomas Rauramaa $\mathrm{MD}^{1,2}$, Maria Pikkarainen $\mathrm{PhD}^{3}$, Elisabet Englund $\mathrm{MD} \mathrm{PhD}^{4}$,

Paul G Ince MD FRCPath ${ }^{5}$, Kurt Jellinger MD PhD ${ }^{6}$, Anders Paetau MD PhD ${ }^{7}$, Laura Parkkinen

$\mathrm{PhD}^{8}$, Irina Alafuzoff $\mathrm{MD} \mathrm{PhD}^{1,3,9}$

${ }^{1}$ Department of Pathology, Kuopio University Hospital, Kuopio Finland

${ }^{2}$ Department of Clinical Medicine, Unit of Pathology, Kuopio University, Kuopio Finland

${ }^{3}$ Department of Clinical Medicine, Unit of Neurology, Section of Neuropathology, Kuopio

University, Kuopio Finland ${ }^{4}$ Department of Pathology, University Hospital, Lund, Sweden

${ }^{5}$ Department of Neurosciences, University of Sheffield, Sheffield, UK

${ }^{6}$ Institute of Clinical Neurobiology, Vienna, Austria ${ }^{7}$ Department of Pathology, University of

Helsinki, Helsinki, Finland ${ }^{8}$ Queen Square Brain Bank for Neurological Disorders, Department of

Molecular Neuroscience, UCL Institute of Neurology, London, UK

${ }^{9}$ Department of Genetics and Pathology, Rudbeck Laboratory, Uppsala University, Uppsala

University Hospital, Uppsala, Sweden

\section{Address correspondence to:}

Prof Irina Alafuzoff, MD, PhD

Uppsala University/Uppsala University Hospital

Department of Genetics and Pathology

Rudbeck Laboratory

Dag Hammarskjölds väg 20

75185 Uppsala Sweden 
E-mail: irina.alafuzoff@genpat.uu.se

\section{ACKNOWLEDGEMENTS}

We thank medical laboratory technologist Tarja Kauppinen, Mrs. Merja Fali, Mr. Heikki

Luukkonen and Mr. Hannu Tiainen for their skilful technical assistance, Vesa Kiviniemi PhD for his assistance with the statistical analyses and Ewen MacDonald $\mathrm{PhD}$ for critical reading of the manuscript. The study has been authorized by the Ethics Committee of Kuopio University Hospital and the Finnish national authority for medicolegal affairs. This study has been supported by UCB Pharma Nordic Epilepsy Grant 2008 and EVO funds from Kuopio University Hospital. The authors report no conflicts of interest.

Full and cover title:

Cardiovascular diseases and hippocampal infarcts

Number of pages: 25

Number of tables: 6

Number of figures: 1

Key words:

post-mortem study, histology, hippocampus, infarct, cardiovascular disease

Grant sponsor: UCB Pharma Nordic Epilepsy Grant 2008 and EVO funds from Kuopio University Hospital. 


\begin{abstract}
Background and Purpose: The prevalence of hippocampal lesions such as hippocampal infarcts have not been studied in detail even though hippocampal alterations are known to be associated with various clinical conditions such as age related degenerative disorders and epilepsy.

Methods: Here we defined the hippocampal infarcts and assessed the prevalence of this lesion in large unselected population of 1245 subjects age ranging from 1 to 99 years (mean age $79 \pm 1$

S.E.M). Furthermore, we assessed the association of these lesions with various cardio- and cerebrovascular disorders and other neurodegenerative lesions.

Result: The prevalence of hippocampal infarct in the study population of 1245 subjects was $12 \%$, increasing to $13 \%$ when only those with a clinically diagnosed cognitive impairment $(n=311)$ were analyzed. Large hemispheric brain infarcts were seen in $31 \%$ of the study subjects and these lesions were strongly associated with cardiovascular risk factors such as hypertension (43\%), coronary disease (32\%), myocardial infarct (22\%), atrial fibrillation (20\%) and heart failure (20\%). In contrast, hippocampal infarcts displayed a significant association only with large hemispheric brain infarct, heart failure and cardiovascular index as assessed post-mortem. It is noteworthy that only widespread hippocampal infarcts were associated with clinical symptoms of cognitive impairment or epilepsy.

Conclusion: The surprisingly low prevalence of $12 \%$ of hippocampal infarcts in aged population found here and the failure to detect an association between this lesion and various cerebro- cardiovascular lesions is intriguing. Whether susceptibility to ischemia in line with susceptibility to neuronal degeneration in this region is influenced by still undetermined risk- factors need further investigation. Furthermore it should be noted that the size of the hippocampal tissue damage, i.e. small vs. large cystic infarcts is of significance regarding clinical alterations.
\end{abstract}




\title{
INTRODUCTION
}

The hippocampal formation is a central part of the limbic system and it is a crucial brain structure for memory functions (Braak et al. 1996, Amaral et al. 2007). The susceptibility of specific neurons within hippocampus to insults such as anoxia, ischemia and hypoglycemia has been documented in both humans and animal models (Schmidt-Kastner and Freund 1991, Harry and d'Hellencourt 2003). Experimental animal studies have shown that in particular damage affecting the cornu Ammonis (CA) 1 subfield can occur as a result of chronic cerebrovascular insufficiency (de la Torre et al. 1992). It is well acknowledged that the hippocampal formation is also affected in many primary age-related neurodegenerative diseases (DelaCourte et al. 2002, Braak et al. 1999, Tolnay and Clavaguera 2004).

\begin{abstract}
As far as we are aware, studies on the prevalence of hippocampal infarcts, i.e., lesions caused by blockage of the tissues blood supply, in a large unselected post-mortem material including both cognitively intact and impaired subjects are largely lacking. Furthermore, there are few reliable assessments of the association between various cardiovascular diseases and hippocampal infarcts.
\end{abstract}

Thus the aim of this study was to investigate the prevalence of hippocampal infarcts in a large postmortem material, including subjects with and without cognitive impairment and to correlate our findings with the clinical data with the emphasis on cardio- and cerebro-vascular diseases. 


\section{MATERIALS AND METHODS}

Subjects

The working order of this study is delineated in the flowchart (Figure 1). Overall, 1245 subject had undergone a clinical autopsy including an examination of the brain during the years $1995-2005$, in the Kuopio University Hospital, unit of pathology. The material consisted of subjects from a longitudinal follow-up study of dementia of Alzheimer's type, of individuals from a prospective longitudinal clinical study of ageing, of a cohort of consecutive clinical post-mortem cases collected for a single year and a sample of Brain Bank material that were not a part of any other previously mentioned study (Parkkinen et al 2001).

\section{Neuropathological assessment}

According to the standard dissection protocol used in the Kuopio University Hospital, the brains were weighed, and then immersed for at least one week in $10 \%$ buffered formalin solution. Before the brains were cut, they were grossly evaluated and the severity of atherosclerosis of the arterial circle of Willis was graded on a 4-step scale, i.e.none- no atherosclerotic plaques were seen, mildscattered atherosclerotic plaques were seen particularly in areas of bifurcations, moderate atherosclerotic changes were obvious as well as focal lesions such that lumen obliteration of up to $50 \%$ was noted and severe - most of the vasculature was affected and focal lesions sufficient to cause lumen obliteration of up to $75 \%$ noted.

Subsequently, the brains were cut into $1 \mathrm{~cm}$ thick coronal slices and grossly visible lesions were assessed on all fixed coronal slices.

Grossly apparent hemispheric brain infarcts were noted according to their location and the primary supplying cerebral artery: Anterior cerebral artery (ACA), medial cerebral artery (ACM), posterior 
cerebral artery $(\mathrm{ACP})$ or cerebellar arteries. In addition, it was noted whether the gross lesions were located in the "watershed" areas.

A cardiovascular index (CVI) was calculated as described earlier (Alafuzoff et al. 1999) from data found in the autopsy records. The CVI was a score ranging from 0 to 15 , based on the semiquantitative estimation of grossly apparent cardiovascular pathology at autopsy (Table 1).

From all cases, brain specimens were taken from at least 16 cortical and subcortical regions. These 16 samples were taken routinely from the macroscopically non-affected side. The brain specimens were embedded in paraffin, cut into $7 \mu \mathrm{m}$-thick sections and stained routinely applying haematoxylin and eosin (HE) stain. In this study the posterior hippocampal section was taken at the level of lateral geniculate body including the whole of Ammons horn and subiculum. The section was taken from the macroscopically non-affected or in cases without grossly notable lesions from the right hemisphere and was investigated for the presence or absence of infarcts as visualized with the HE stain.

A hippocampal infarct was defined as the area in which the neuropil was either relatively preserved or loosened with vacuolization. The vacuoles could merge and have formed cystic spaces of various sizes ranging from 0.01 to a few millimetres in diameter. The margins of this lesion towards the intact grey matter could display rounded edges. Within the lesions, occasional or numerous haemosiderin-containing macrophages or prominent vascular proliferation or gliosis can be noted. In these analyses, the subjects with infarcts were sub-grouped into those with small microscopic infarcts and those with large confluent cystic lesion affection the whole of CA1 region. 
Microscopic infarcts elsewhere than in hippocampus were searched for from all sampled sections including specimens taken from frontal, temporal, parietal, precentral, occipital cortices, gyrus cinguli, striatum, basal forebrain including amygdala, thalamus and midbrain including substantia nigra, pons including locus ceruleus, medulla, vermis and cerebellar cortex.

\section{Clinical assessment}

In order to harmonize the material from a clinical point, all cases included in the study (Figure 1) with a primary or metastatic brain tumour, infectious disease in the central nervous system or those who had suffered from a ruptured aneurysm were excluded.

The clinical data was collected retrospectively from the autopsy referrals and when needed from the original medical records. The clinical parameters that were monitored were the presence/absence of common cardiovascular and metabolic alterations, i.e. arterial hypertension (HT), peripheral artery disease (PAD) in the lower extremities, coronary disease (CD), myocardial infarct (MI), atrial fibrillation (AF), heart failure (HF), transient ischemic attacks (TIA), stroke, diabetes mellitus (DM) both type I and type II. The diagnosis of dementia, below given as cognitive impairment (CI), was based on NINCDS-ADRDA (McKhann et al. 1984) and DSM-III-R criteria. However, some of the cases, which had been classified as non-demented, may have displayed mild cognitive impairment that had not been recognised during their lifetime, though it is unlikely that the presence of full blown dementia would have been overlooked. Furthermore, it was recorded if the medical records showed any indications if the subjects had ever suffered from epilepsy.

\section{Immunohistochemistry}

Hyperphosphorylated $\tau(\mathrm{HP} \imath), \beta$-amyloid (A $\beta)$ and $\alpha$-synuclein $(\alpha \mathrm{S})$ pathology were visualized by immunohistochemical (IHC) methods. Details regarding the staining procedures are given in table 2. HPt immunoreactivity was assessed in three sections (hippocampal section, temporal and 
occipital cortices) and the results are given as an Alzheimer's disease related HPı stage (Braak et al. 2006, Alafuzoff et al. 2008), A $\beta$ parenchymal aggregates and cerebral amyloid angiopathy (CAA) were assessed as being absent or present in at least one of the three cortical sections investigated (frontal, parietal and temporal cortices) and $\alpha \mathrm{S}$ was assessed as being absent or present in at least one of three neuroanatomical regions assessed (dorsal motor nucleus of vagus, substantia nigra, amygdaloid nucleus).

Statistical analysis

The statistical analysis was conducted with SPSS 16 for Windows. Differences between the study group and controls were tested applying t-test, Fisher's exact test and the nonparametric MannWhitney U test. The association between various parameters was assessed by logistic regression analysis employing odds ratio with the $95 \%$ confidence interval. 


\section{RESULTS}

An infarct in hippocampus as defined here was identified in 150 cases $(12 \%)$ out of the 1245 cases. Agreement regarding the assessment of hippocampal pathology i.e. infarct or no infarct was $76 \%$ when four independent neuropathologists reassessed the haematoxylin-eosin stained sections. In 116 subjects out of these 150 all of the data required for this study was available and their mean age \pm S.E.M at death was $79 \pm 1$ years. The mean age of the control group, 96 subjects, lacking a hippocampal infarct was $75 \pm 1$ years. The distribution of gender and the brain weights did not differ statistically between these two groups. In the following analysis the material was divided into three age groups 54-65, 66-80 and 81-95 years of age. Out of the original 1245 subjects, $311(25 \%)$ had displayed cognitive impairment during their lifetime. Forty (13\%) of these 311 cognitively impaired subjects displayed an infarct in hippocampus.

The prevalences of cardiovascular diseases, diabetes mellitus, cognitive impairment and epilepsy in the study groups are summarized in tables 3 and 4 . In subjects with hippocampal infarct (Table 3) heart failure was significantly $(\mathrm{p}<0.05)$ more common when compared with the control group (29\% vs. $16 \%)$. The prevalence of stroke was significantly higher $(\mathrm{p}<0.05)$ in subjects with hippocampal infarct when compared with controls (29\% vs. 16\%) difference being highest in the youngest group (44\% vs 5\%). This difference however disappeared in the oldest age group. Hippocampal infarct was seen in $69 \%$ of subjects with clinical stroke and in $71 \%$ of subjects with grossly apparent hemispheric lesions. There were no significant differences when the prevalences of peripheral artery disease in the lower extremities, coronary disease, myocardial infarct, atrial fibrillation, transient ischemic attacks and diabetes mellitus were compared. 
The prevalence of hypertension, peripheral artery disease in the lower extremities, heart disease such as coronary disease, myocardial infarct, atrial fibrillation and heart failure in 49 subjects with clinical diagnosis of stroke was here $45 \%, 8 \%, 35 \%, 20 \%, 20 \%$ and $18 \%$, respectively.

The neuropathological investigation revealed that the prevalence of the above risk factors in the 65 subjects with a grossly notable cerebral infarct, i.e. neuropathologically verified stroke, was $43 \%$, $6 \%, 32 \%, 22 \%, 20 \%, 20 \%$, respectively.

The prevalences of cognitive impairment and epilepsy were comparable in the subjects with and without hippocampal infarcts (Table 4). Cognitive impairment was present in $56 \%$ of subjects with a large cystic infarct when compared with $31 \%$ in subjects with small infarcts. Twenty two percent of subjects with large cystic infarcts had suffered from epilepsy, a frequency that was significantly different $(\mathrm{p}<0.05)$ when compared with the 3 percent of subjects with small infarcts.

Postmortem findings, including detailed neuropathological findings are summarized in tables 5 and 6. The CVI was significantly $(\mathrm{p}<0.01)$ higher $(9.3 \pm 0.2$ and $8.4 \pm 0.3)$ in subjects with a hippocampal infarct when compared with controls. The prevalences of gross and microscopic infarcts elsewhere than in hippocampus were significantly $(\mathrm{p}<0.01$ and $\mathrm{p}<0.05)$ higher in subjects with a hippocampal infarct ( $40 \%$ vs. $20 \%$ and $49 \%$ vs. $34 \%)$.

There were no statistically significant differences when the primary arterial distribution or the hemispheric localization of the gross infarcts was analyzed between subjects with and without hippocampal infarcts. The number and distribution of "watershed" infarcts did not differ between the two groups. The gross cerebral infarcts were less commonly multiple in subjects without 
hippocampal infarcts (26\% vs. $37 \%$ ) however this difference was not statistically significant. The prevalence of lacunar state changes did not differ significantly between the two groups.

There were no significant differences in the presence of $\alpha \mathrm{S}, \mathrm{A} \beta$ and CAA in subjects with or without a hippocampal infarct. The AD related HP $\tau$ stage did not differ significantly between the two study groups.

Logistic regression analysis adjusted for confounding factors included in this study revealed that the age at death differed significantly between the subjects with and without a hippocampal infarct $(\mathrm{p}=0.04)$. 


\section{DISCUSSION}

Here we report that the prevalence of a hippocampal infarct, i.e. vascular lesion, is seen in $12 \%$ of subjects in a large unselected postmortem material including as many as 1245 subjects. To our knowledge this is the first report assessing the prevalence of hippocampal vascular lesions in an large unselected human postmortem material. Previous studies reporting the prevalence of hippocampal lesions have in general included a selected patient cohort, i.e. subjects with a clinical disorder such as cognitive impairment. Thus, hippocampal microinfarcts have been reported to be seen in as many as $44 \%$ of subjects with both AD and cerebral infarcts (Del Ser et al. 2005). Out of our original 1245 cases, only $25 \%$ had displayed cognitive impairment during their lifetime and out of these in only $13 \%$ was hippocampal infarct as defined here seen. Thus the prevalence of hippocampal infarct in our study differs significantly from the values reported previously (Del Ser et al. 2005). There are some issues that might partly explain these differences. Firstly, a selection bias might alter the results. In 2001, it was reported that the prevalence of $\alpha$ S pathology was significantly altered by the selection strategy such that it could range from 8-27\% (Parkkinen et al. 2001). Secondly, most previous reports lack a detailed definition of the hippocampal lesion being assessed. In age related degenerative disorders such as AD and frontotemporal lobar degeneration, the hippocampus is severely affected and this has been described by many investigators as a hippocampal sclerosis due to the degenerative process (Amador-Ortiz et al 2007 ). This type of lesion might be difficult to differentiate from a true vascular alteration. More importantly these two lesions might well coexist and thus making the differentiation even more difficult. Here we included only those cases that displayed an indisputable vascular hippocampal lesion and thus cases with cell loss within the CA1 region without changes in the neuropil were not included. Thirdly, in this study we carried out a histological assessment of hippocampus unilaterally and assessed only 
the posterior art at the level of geniculate body. Whether hippacampus was histologically assessed uni- or bilaterally in the referred study with higher percentage of cases with lesions is not clear.

Cardiovascular diseases including hypertension, peripheral artery disease in the lower extremities, various heart and cerebrovascular diseases are considered as risk factors for large brain infarcts and stroke (Allen and Bayraktutan 2008, Aronow 2008). In line with previous reports, the cardiovascular risk factors studied here were strongly associated with clinical stroke and/or grossly apparent cerebral infarcts.

In our material the hippocampal infarcts were seen in $69 \%$ of subjects with clinical stroke and in $71 \%$ of subjects with grossly apparent hemispheric lesions. Thus there was an association between stroke/grossly apparent infarct and hippocampal lesions. The association found between stroke and hippocampal infarcts might not only be related to an alteration in the cerebral circulation in the event of a stroke, but might be explained by the fact that the hippocampus is located in the uncal area. The increased intracranial pressure due to a supratentorial lesion, i.e. large infarct, increases the pressure in the tentorial slit altering the circulation to the hippocampus leading to a hippocampal lesion.

In line with the above, there was an association between heart failure and hippocampal lesions that also was most evident in the youngest age group. Heart failure is frequently associated with respiratory insufficiency and thus the combination of circulatory failure and hypoxia might explain the frequent finding of hippocampal infarcts in this group (Agostoni et al 2007).

To our surprise, no significant difference was noted with regard to cardiovascular risk factors such as hypertension, peripheral artery disease in the lower extremities, atrial fibrillation and myocardial 
infarct when comparing subjects with and without a hippocampal infarct. It is noteworthy, however, that the cardiovascular index, a post-mortem estimate of the cardiovascular status, was significantly higher in subjects with large infarcts as well as, in those with hippocampal infarct. These results indicate that a large hemispheric infarct and a hippocampal infarct can have both differing and common risk factors. A shared ethiology is supported by the finding that in $49 \%$ of subjects with a hippocampal infarct, solitary or multiple microscopic infarcts were found elsewhere in the brain.

Previous reports have suggested that 1) congestive heart failure and cerebral hypoperfusion may cause cognitive impairment (Cohen and Mather 2007), that 2) cerebral hypoperfusion can generate cortical watershed microinfarcts (Suter et al. 2002) and 3) that solitary or multiple small infarcts, i.e. strategic infarcts that are located in functionally important brain areas, including the hippocampus, may be important in the clinical syndrome of dementia (Jellinger 2008). In line with the above we noted that in subjects with large cystic infarcts the prevalence of cognitive impairment was indeed $56 \%$. It is noteworthy however that cognitive impairment was noted in only $33 \%$ of subjects with histologically verified small or large hippocampal infarct. Thus, an infarct as such is not in itself associated with cognitive impairment whereas the presence of a large cystic infarct in hippocampus is sufficient to alter cognition, once more emphasizing the importance of a detailed definition of the lesion being investigated.

Based on our findings, there was no association between hippocampal infarct and the most common age related degenerative lesion such as $\mathrm{A} \beta$ aggregation, $\mathrm{HP} \tau$ and $\alpha \mathrm{S}$. This is in line with previous reports suggesting that cardiovascular disease in aged and demented patients is not directly associated with the load of degenerative lesions e.g. amounts of $\mathrm{A} \beta, \operatorname{HP} \tau$ or $\alpha \mathrm{S}$ (Alafuzoff et al. 1999, Aho et al. 2006, Aho et al. 2008). 
Hippocampal sclerosis defined as segmental loss of pyramidal neurons, granule cell dispersion and reactive gliosis is a common finding in patients with temporal lobe epilepsy (Blümcke 2002). Epilepsy was diagnosed in $4 \%$ of the subjects with hippocampal infarct and in $5 \%$ of subjects without a hippocampal infarct. Interestingly, as many as $22 \%$ of subjects with a large cystic lesion in the hippocampus had been diagnosed with epilepsy during their lifetime indicating that a widespread alteration in the CA1 region is strongly associated not only with cognitive impairment but as well with epilepsy. The number of subjects with large cystic infarct was small and thus the found relationships with cognitive impairment and/or epilepsy needs to be further investigated.

In conclusion, to the best of our knowledge, this is the first study in which the prevalence of hippocampal infarct defined in detail has been studied in a large, unselected postmortem material. The prevalence of $12 \%$ was lower than expected when taking into consideration the known susceptibility of hippocampal neurons to a wide variety of insults (Harry and d'Hellencourt 2003). Only widespread hippocampal infarcts were significantly associated with both cognitive impairment or with epilepsy indicating that a substantial area of CA1 region has to be altered for development of clinical symptoms. 


\section{REFERENCES}

1. Agostoni P, Cattadori G, Bussotti M, Apostolo A (2007) Cardiopulmonary interaction in heart failure. Pulm Pharmacol Ther. 20:130-4.

2. Aho L, Jolkkonen J, Alafuzoff I. 2006. Beta-amyloid aggregation in human brains with cerebrovascular lesions. Stroke. 37:2940-5.

3. Aho L, Parkkinen L, Pirttila T, Alafuzoff I. 2008. Systematic appraisal using immunohistochemistry of brain pathology in aged and demented subjects. Dement Geriatr Cogn Disord. 25:423-32.

4. Alafuzoff I, Helisalmi S, Mannermaa A, Riekkinen P Sr., Soininen H. 1999. $\beta$-amyloid load is not influenced by the severity of cardiovascular disease in aged and demented patients. Stroke. $30: 613-8$

5. Alafuzoff I, Arzberger T, Al-Sarraj S, Bodi I, Bogdanovic N, Braak H, Bugiani O, Del-Tredici K, Ferrer I, Gelpi E, Giaccone G, Graeber MB, Ince P, Kamphorst W, King A, Korkolopoulou P, Kovács GG, Larionov S, Meyronet D, Monoranu C, Parchi P,Patsouris E, Roggendorf W, Seilhean D, Tagliavini F, Stadelmann C,Streichenberger N, Thal DR, Wharton SB, Kretzschmar H. 2008. Staging of neurofibrillary pathology in Alzheimer's disease: a study of the Brain Net Europe Consortium. Brain Pathol.18:484-96.

6. Allen CL, Bayraktutan U. Risk factors for ischaemic stroke. 2008. Int J Stroke. 3:105-16. 
7. Amador-Ortiz C, Lin W-L, Ahmed Z, Personett D, Davies P, Duara R, Graff-Radford NR, Hutton ML, Dickson DW. 2007. TDP-43 immunoreactivity in hippocampal sclerosis in Alzheimer's disease Ann Neurol 61:435-445.

8. Amaral DG, Lavenex P. 2007. Hippocampal neuroanatomy. In: Andersen P, Morris R, Amaral D, Bliss T, O’Keefe J. Editors. The Hippocampus Book. Oxford University Press; New York: p. 872

9. Aronow WS. 2008. Treatment of hypertension in the elderly. Geriatrics. 63:21-5.

10. Blümcke I, Thom M, Wiestler OD. 2002. Ammon's horn sclerosis: a maldevelopmental disorder associated with temporal lobe epilepsy. Brain Pathol.12:199-211

11. Braak H, Braak E, Yilmazer D, Bohl J. 1996. Functional anatomy of human hippocampal formation and related structures. J Child Neurol.11:265-75

12. Braak E, Griffing K, Arai K, Bohl J, Bratzke H, Braak H. 1999. Neuropathology of Alzheimer's disease: what is new since A. Alzheimer? Eur Arch Psychiatry Clin Neurosci. 249 Suppl 3:14-22

13. Braak H, Alafuzoff I, Arzberger T, Kretzschmar H, Del Tredici K.2006. Staging of Alzheimer disease-associated neurofibrillary pathology using paraffin sections and immunocytochemistry. Acta Neuropathol.112:389-404.

14. Cohen MB, Mather PJ. 2007. A review of the association between congestive heart failure and cognitive impairment. Am J Geriatr Cardiol. 16:171-4. 
15. Delacourte A, Sergeant N, Wattez A, Maurage CA, Lebert F, Pasquier F, David JP. 2002. Tau aggregation in the hippocampal formation: an ageing or a pathological process? Exp Gerontol. 37:1291-1296. Review.

16. de la Torre JC, Fortin T, Park GA, Butler KS, Kozlowski P, Pappas BA, de Socarraz H, Saunders JK, Richard MT. 1992. Chronic cerebrovascular insufficiency induces dementia-like deficits in aged rats. Brain Res. 2:186-95

17. Del Ser T, Hachinski V, Merskey H, Munoz DG. 2005. Alzheimer's disease with and without cerebral infarcts. J Neurol Sci. 15;231:3-11.

18. Fillit H, Nash DT, Rundek T, Zuckerman A. 2008. Cardiovascular risk factors and dementia. Am J Geriatr Pharmacother. 6:100-18.

19. Harry GJ, d'Hellencourt CL. 2003. Dentate Gyrus: Alterations that Occur with Hippocampal Injury. Neurotoxicology 24:343-356

20. Jellinger KA. 2008. Morphologic diagnosis of "vascular dementia“- A critical update. J Neurol Sci 270:1-12.

21. McKhann G, Drachman D, Folstein M, Katzman R, Price D, Stadlan EM. 1984. Clinical diagnosis of Alzheimer's disease: report of the NINCDS-ADRDA Work Group under the auspices of Department of Health and Human Services Task Force on Alzheimer's Disease. Neurology. $34: 939-44$. 
22. Parkkinen L, Soininen H, Laakso M, Alafuzoff I. 2001. Alpha-synuclein pathology is highly dependent on the case selection. Neuropathol Appl Neurobiol. 27:314-25.

23. Schmidt-Kastner R, Freund TF. 1991. Selective vulnerability of the hippocampus in brain ischemia. Neuroscience 40:599-636

24. Suter OC, Sunthorn T, Kraftsik R, Straubel J, Darekar P, Khalili K, Miklossy J.

2002. Cerebral hypoperfusion generates cortical watershed microinfarcts in Alzheimer disease Stroke. 33:1986-92.

25. Tolnay M, Clavaguera F. 2004. Argyrophilic grain disease: A late-onset dementia with distinctive features among tauopathies. Neuropathology 24:269-283 


\section{FIGURE LEGENDS}

Figure 1. Flowchart summarising the working arrangement in this study. 
Table 1. Cardiovascular index (CVI) assessed at autopsy (9)

\begin{tabular}{lcccc}
\hline Type of variable & 0 & 1 & 2 & 3 \\
\hline Heart weight, g & $<250$ & $251-325$ & $326-400$ & $>400$ \\
\hline Coronary arteriosclerosis & No & Mild & Moderate & Severe \\
\hline Coronary thrombosis & No & Yes & $\ldots$ & $\ldots$ \\
\hline $\begin{array}{l}\text { Lesions consistent with } \\
\text { acute myocardial } \\
\text { infarction }\end{array}$ & No & Yes & $\ldots$ & $\ldots$ \\
\hline $\begin{array}{l}\text { Lesions consistent with } \\
\text { old myocardial infarction }\end{array}$ & No & Yes & $\ldots$ & $\ldots$ \\
\hline $\begin{array}{l}\text { Generalized } \\
\text { arteriosclerosis (aorta, } \\
\begin{array}{l}\text { AR }{ }^{*}, \text { AMS } \\
\text { ) }\end{array}\end{array}$ & No & Mild & Moderate & Severe \\
\hline $\begin{array}{l}\text { Arteriosclerosis of circle } \\
\text { of Willis }\end{array}$ & No & Mild & Moderate & Severe \\
\hline $\begin{array}{l}\text { Sum of CVI } \\
*\end{array}$ & & & \\
\hline arteria renalis ${ }^{\dagger}$ arteria mesenterica superior. & &
\end{tabular}


Table 2. Immunohistochemistry

\begin{tabular}{llllll}
\hline Antibody & Source & Clone & Pretreatment & Dilution & Chromogen \\
\hline$\beta$-amyloid & Dako, M0872 & 6F/3D & $80 \%$ FA, 6 hours & $1: 100$ & Vector Red \\
\hline hyperphosphorylated- $\tau$ & Innogenetics, BR-03 & AT8 & - & $1: 500$ & Diaminobenzidine \\
\hline$\alpha$-synuclein & Novocastra NCL-ASYN & KM51 & $80 \%$ FA, 5 minutes & $1: 1000$ & Romulin AEC \\
\hline
\end{tabular}

FA - formic acid, incubation carried out at $4+C$ overnight 
Table 3. Presence of cardio- and cerebro-vascular disorders and/or diabetes mellitus in subjects with or without hippocampal infarct.

\begin{tabular}{|c|c|c|c|c|c|c|c|c|c|c|c|c|c|c|c|c|c|c|c|c|}
\hline \multirow{3}{*}{$\begin{array}{l}\text { Hippocampal } \\
\text { status }\end{array}$} & \multirow{3}{*}{$\begin{array}{l}\text { Age } \\
\text { group }\end{array}$} & \multirow[t]{3}{*}{$\mathrm{n}$} & \multicolumn{2}{|c|}{ HT } & \multicolumn{2}{|c|}{ PAD } & \multicolumn{8}{|c|}{ Heart disease } & \multicolumn{4}{|c|}{ Brain disorders } & \multicolumn{2}{|c|}{$\mathrm{DM}$} \\
\hline & & & \multirow[b]{2}{*}{$\mathrm{n}$} & \multirow[b]{2}{*}{$\%$} & \multirow[b]{2}{*}{$\mathrm{n}$} & \multirow[b]{2}{*}{$\%$} & \multicolumn{2}{|c|}{$\mathrm{CD}$} & \multicolumn{2}{|c|}{ MI } & \multicolumn{2}{|c|}{$\mathrm{AF}$} & \multicolumn{2}{|c|}{$\mathrm{HF}$} & \multicolumn{2}{|c|}{ TIA } & \multicolumn{2}{|c|}{ STROKE } & \multirow[b]{2}{*}{$\mathrm{n}$} & \multirow[b]{2}{*}{$\%$} \\
\hline & & & & & & & $\mathrm{n}$ & $\%$ & $\mathrm{n}$ & $\%$ & $\mathrm{n}$ & $\%$ & $\mathrm{n}$ & $\%$ & $\mathrm{n}$ & $\%$ & $\mathrm{n}$ & $\%$ & & \\
\hline \multirow{4}{*}{ Infarct } & $54-65$ & 9 & 3 & 33 & - & & 1 & 11 & 2 & 22 & - & & 3 & 33 & 1 & 11 & $4^{*}$ & 44 & 4 & 44 \\
\hline & $66-80$ & 52 & 19 & 37 & 3 & 6 & 15 & 29 & 10 & 19 & 13 & 25 & 9 & 17 & 3 & 6 & $20 *$ & 39 & 8 & 15 \\
\hline & $81-95$ & 55 & 18 & 33 & 4 & 7 & 22 & 40 & 7 & 13 & 11 & 20 & 22 & 40 & 3 & 6 & 10 & 18 & 13 & 24 \\
\hline & All & 116 & 40 & 35 & 7 & 6 & 38 & 33 & 19 & 16 & 24 & 21 & $34 *$ & 29 & 7 & 6 & $34 *$ & 29 & 25 & 22 \\
\hline \multirow{4}{*}{ No infarct } & $54-65$ & 20 & 8 & 40 & 1 & 5 & 2 & 10 & 2 & 10 & 1 & 5 & 1 & 5 & 1 & 5 & $1 *$ & 5 & 3 & 15 \\
\hline & $66-80$ & 42 & 12 & 29 & - & & 17 & 41 & 7 & 17 & 5 & 12 & 2 & 5 & 6 & 14 & $8^{*}$ & 19 & 12 & 29 \\
\hline & $81-95$ & 34 & 14 & 41 & 2 & 6 & 13 & 38 & 5 & 15 & 11 & 32 & 12 & 35 & 2 & 6 & 6 & 18 & 4 & 12 \\
\hline & All & 96 & 34 & 35 & 3 & 3 & 32 & 33 & 14 & 15 & 17 & 18 & $15^{*}$ & 16 & 9 & 9 & $15^{*}$ & 16 & 19 & 20 \\
\hline
\end{tabular}

n-number, HT- Arterial hypertension, PAD- Peripheral artery disease of lower extremities, CD- Coronary disease, MI-Myocardial infarct, AFAtrial fibrillation, HF- Heart failure, TIA-Transient ischaemic attact, DM-Diabetes mellitus Fisher's exact test when comparing subjects with and without an infarct $* \mathrm{p}<0,05$ 
Table 4. Presence of cognitive impairement (CI) and epilepsy (EP) in subjects with hippocampal infarcts when subdivided according to whether they displayed small and large lesions

\begin{tabular}{lcccccc}
\hline Hippocampal status & $\mathrm{n}$ & \multicolumn{2}{c}{ CI } & \multicolumn{2}{c}{ EP } \\
\cline { 3 - 6 } & & $\mathrm{n}$ & $\%$ & $\mathrm{n}$ & $\%$ \\
\hline with infarct & 116 & 38 & 33 & 5 & 4 \\
\hline small & 107 & 33 & 31 & $3 *$ & 3 \\
\hline large cystic & 9 & 5 & 56 & $2 *$ & 22 \\
\hline no infarct & & & & & & \\
\hline
\end{tabular}

Fisher's exact test when comparing subjects with and without infarct * $\mathrm{p}<0,05$ 
Table 5. Postmortem data including neuropathological findings in subjects with and without hippocampal infarct

\begin{tabular}{|c|c|c|c|c|c|c|c|c|c|c|c|c|c|c|c|c|c|c|}
\hline \multirow{4}{*}{$\begin{array}{c}\text { Hippocampal } \\
\text { Status }\end{array}$} & \multirow{4}{*}{$\begin{array}{l}\text { Age } \\
\text { groups }\end{array}$} & \multirow[t]{4}{*}{$\mathrm{n}$} & \multirow{4}{*}{$\begin{array}{l}\text { Age at } \\
\text { death } \\
m \pm S . E\end{array}$} & \multirow{4}{*}{$\begin{array}{c}\text { Gender } \\
\text { F/M }\end{array}$} & \multirow{4}{*}{$\begin{array}{c}\mathrm{CVI} \\
\mathrm{m} \pm \mathrm{SE}\end{array}$} & \multirow{4}{*}{$\begin{array}{c}\mathrm{BW} \\
\text { in grams } \\
\mathrm{m} \pm \mathrm{SE} .\end{array}$} & \multicolumn{12}{|c|}{ Concomitant brain pathology } \\
\hline & & & & & & & \multicolumn{2}{|c|}{$\mathrm{VaL}$} & \multicolumn{4}{|c|}{ AD related $\mathrm{HP} \imath$ stage } & \multicolumn{4}{|c|}{ with $A \beta$} & \multicolumn{2}{|c|}{ with $\alpha \mathrm{S}$} \\
\hline & & & & & & & \multirow[t]{2}{*}{ gross } & \multirow[t]{2}{*}{ micro } & \multirow[t]{2}{*}{0} & \multirow[t]{2}{*}{ I-II } & \multirow[t]{2}{*}{ III-IV } & \multirow[t]{2}{*}{ V-VI } & \multicolumn{2}{|c|}{$\mathrm{A} \beta$} & \multicolumn{2}{|c|}{ CAA } & \multirow[b]{2}{*}{$\mathrm{n}$} & \multirow[b]{2}{*}{$\%$} \\
\hline & & & & & & & & & & & & & $\mathrm{n}$ & $\%$ & $\mathrm{n}$ & $\%$ & & \\
\hline \multirow{5}{*}{$\begin{array}{l}\text { with } \\
\text { infarct }\end{array}$} & $54-65$ & 9 & $60 \pm 1$ & $3 / 6$ & $7.8 \pm 1.1$ & $1426 \pm 71$ & $5 *$ & 5 & 6 & 3 & - & - & 1 & 11 & - & - & - & - \\
\hline & $66-80$ & 52 & $75 \pm 1$ & $25 / 27$ & $9.3 \pm 0.4$ & $1379 \pm 19$ & $29 *$ & 22 & 11 & 37 & 1 & 3 & 22 & 42 & 6 & 12 & 14 & 27 \\
\hline & $81-95$ & 55 & $86 \pm 1$ & $35 / 20$ & $9.6 \pm 0.3$ & $1271 \pm 17$ & 12 & 30 & 3 & 31 & 14 & 7 & 40 & 73 & 12 & 22 & 7 & 13 \\
\hline & All & 116 & $79 \pm 1 \dagger \dagger$ & $63 / 53$ & $9.3 \pm 0.2 \dagger \dagger$ & $1331 \pm 14$ & $46 * *$ & $57 *$ & 20 & 71 & 15 & 10 & 63 & 54 & 18 & 16 & 21 & 18 \\
\hline & $54-65$ & 20 & $59 \pm 1$ & $3 / 17$ & $6.6 \pm 0.5$ & $1452 \pm 47$ & $2 *$ & 6 & 19 & 1 & - & - & 2 & 10 & - & - & - & - \\
\hline \multirow{3}{*}{$\begin{array}{c}\text { no } \\
\text { infarct }\end{array}$} & $66-80$ & 42 & $74 \pm 1$ & $16 / 26$ & $9.0 \pm 0.4$ & $1360 \pm 22$ & $12^{*}$ & 11 & 6 & 25 & 6 & 5 & 21 & 50 & 8 & 19 & 8 & 19 \\
\hline & $81-95$ & 34 & $86 \pm 1$ & $24 / 10$ & $8.7 \pm 0.4$ & $1292 \pm 20$ & 5 & 16 & 1 & 19 & 8 & 6 & 23 & 68 & 12 & 35 & 6 & 18 \\
\hline & All & 96 & $75 \pm 1+\dagger$ & $43 / 53$ & $8.4 \pm 0.3 \dagger \dagger$ & $1355 \pm 16$ & $19 * *$ & $33^{*}$ & 26 & 45 & 14 & 11 & 46 & 48 & 20 & 21 & 14 & 15 \\
\hline
\end{tabular}

$\mathrm{m} \pm$ S.E. - mean \pm standard error of means, n-number, F-female, M-male, CVI-cardiovascular index as given in table 2 , BW-brain weight in grams, VaL- cerebrovascular lesion, gross - gross infarcts, micro - microscopic infarcts elsewhere than in hippocampus, AD-Alzheimer's disease, HPi hyperphosphorylated $1, A \beta-\beta$ amyloid, CAA- cerebral amyloid angiopathy and $\alpha \mathrm{S}-\alpha$ Synuclein AD related HPı changes as recommended by BrainNet Europe (Alafuzoff et al 2008). For statistical analyses when comparing subjects with and without an infarct Fisher's exact test $* p<0.05$, ** $\mathrm{p}<0.01 ;$ Student's t- test $\dagger \mathrm{p}<0.05 \dagger \dagger \mathrm{p}<0.01$. 
Table 6. Type and distribution of infarcts in subjects with and without hippocampal infarct

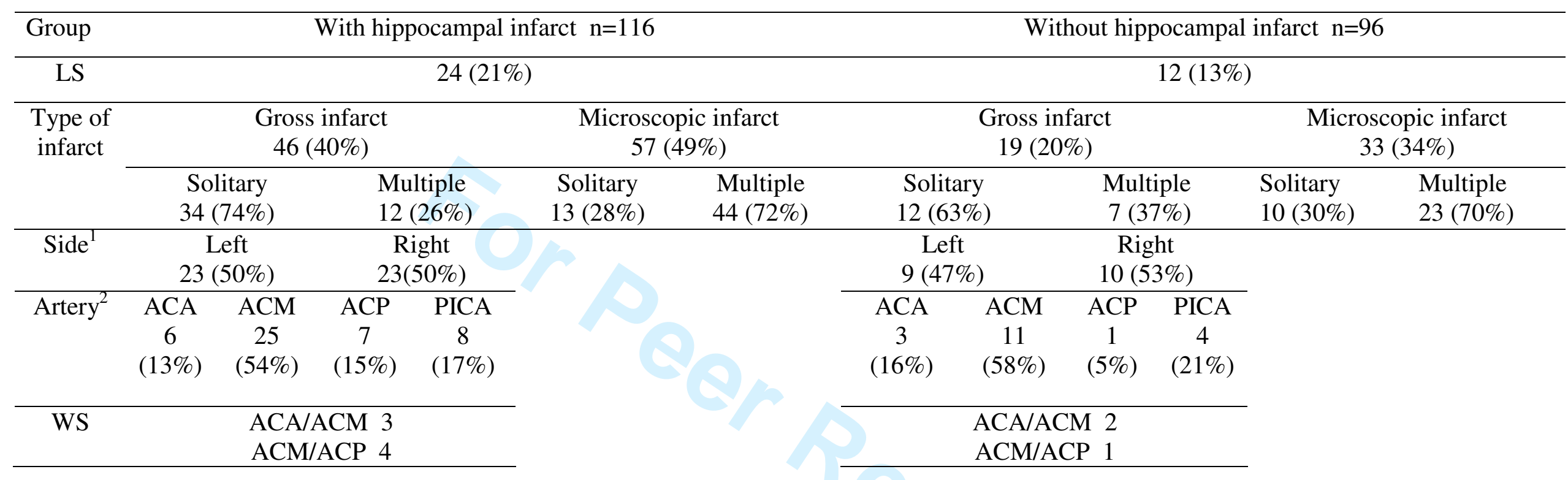

ACA - Anteria cerebri arterior, ACM - arteria cerebri media, ACP - arteria cerebri posterior, PICA - posterior inferior cerebellar artery, LS - lacunar state changes, WS- watershead area, ${ }^{1}$ - side of the gross infarct, ${ }^{2}$ - Primary arterial distribution of the gross infarct 
